\title{
THE HUMAN ELEMENT IN THE JUDICIAL PROCESS
}

\author{
L.-P. PIGEON*
}

The imprecision in ascertaining facts and the uncertainty in laws is the subject of this article. The author discusses this in the framework of judicial discretion by examining the strengths and weaknesses of the exercise in discretion. He recognizes that judges do not blindly apply fixed laws by emphasizing the unavoidable imprecision in the law and the exercise of judicial discretion in making law. The author concludes by pointing out the existence of personal factors which enter into the judicial decision-making process and the tremendous social importance of the selection of members of a judiciary.

Mr. Chief Justice Marshall said:" "Judicial power is never exercised for the purpose of giving effect to the will of the judge; always for the purpose of giving effect to the will of the legislature; or in other words, to the will of the law." On this Cardozo comments: ${ }^{2}$ "It has a lofty sound; it is well and finely said; but it can never be more than partly true."

The doctrine of separation of powers aims at "government by laws and not men". However, the application of this principle to the judicial process suffers from two factors of uncertainty: the first is the difficulty of finding the facts necessary to found a decision in each particular case, the second is the degree of indefiniteness inherent in practically every legislative enactment. The imprecision of the process of ascertaining the relevant facts is well known although often underrated: contrary to popular opinion, facts do not speak for themselves. The large measure of uncertainty inevitably present in written as well as in unwritten laws is perhaps not so well recognized. I will attempt to show that in spite of the utmost care taken to express legislative intentions as clearly as possible, a varying but surprisingly large degree of imprecision is generally unavoidable.

Shortly after the Second World War, the Income War Tax Act was replete with provisions for administrative discretion. The elimination of a good many such provisions was one of the main features of the 1948 Income Tax Act. A determined attempt was made to enact a precise and explicit law under which the tax payable in every case would depend on ascertainable facts and not on the judgment of officials in the Revenue Department. Provisions for administrative discretion were therefore reduced to what was considered a minimum consonant with effective administration. Experience in the application of the new law promptly revealed that, in many situations, advantage was being taken of the new precision for avoiding taxation under circumstances in which, from an administrative point of view, it ought to have been levied. As a result, new rules were devised to plug the loopholes and the act grew in volume and complexity. A few years ago, the attempt to rely exclusively on explicit rules was finally abandoned with respect to the

- The Honourable Mr. Justice Louis-Phillppe Pigeon, Justice of The Supreme Court of Canada. This article was the subject of a speech given by the author to the Canadian Judicature Society at its annual meeting in Ottawa in September, 1969.

1 Osborn v. Bank of the United States (1824) 9 Wheat. 738 at 866.

2 Cardozo, The Nature of the Judicial Process 169. 
important problems known as "dividend stripping" and "associated corporations". An administrative discretion was reestablished subject, however, to a right of appeal to the courts.

Apart from such provisions which clearly require judges to make the law to a certain extent rather than only to interpret it, seeing that any attempt to express fully the legislative intention is thereby abandoned, a great many legislative provisions formulate rules in a language that is largely indefinite. An illustration that immediately comes to mind is the motor vehicle passenger liability restriction to cases of gross negligence. The concept of "negligence" itself is very far from being perfectly precise and a vast area of law-making power is hidden in the duty of concretely defining it in its application to a changing world. Its imprecision is magnified by requiring the courts to decide when it is "gross" and when it is not so.

In fact no rule is really precise unless it can be reduced to a mathematical expression applicable to a factor susceptible of accurate measurement. Such reduction is undoubtedly very convenient. In many instances, it is indeed absolutely essential to practical administration. No one would think of defining the voting age otherwise than by reference to a definite number of years after birth. No one also would, I think, wish to define otherwise the offender to be considered as "juvenile" although nobody suggests that when a youngster is brought into court as a witness instead of an accused, an arbitrary rule should be devised to ascertain his qualifications as a witness instead of requiring the judge to form an individual opinon thereon.

These illustrations show that the reduction of a legal rule to a mathematical expression is often a kind of mixed blessing. Perfect precision in the expression is attained but at the cost of imperfect correlation with reality. Someone has said that "pure mathematics are a science in which one never knows whether what he says is true or false in fact and one does not care". When a mathematical expression is resorted to, the perfect precision of the enactment tends to obscure the fact that the fairness of its application depends on the precision of the measurement and on the correlation of the measured factor with the condition of which it is taken to be an index. This correlation may, in actual fact and depending on individual cases, be far from perfect as, for instance, age and maturity. The reduction of a rule to a mathematical expression results in justice being administered without any possibility of taking account of the imperfection of the correlation.

As another illustration, let us consider the question of impairment by alcohol. At the present time, the determination is made on the basis of evidence of observations of behaviour. On that basis it is judged whether, in each individual case, the condition of the accused was such that it can properly be termed "impairment" because it is only when the effects of alcohol were manifest to a substantial degree that an accused can be convicted for impaired driving. There is no need for elaborate reasoning to show that inevitably and unavoidably there is a wide margin for subjective appreciation of what is "impairment." Under breathalizer legislation, the legal situation is radically changed. The only substantial question becomes: "What is the result of the prescribed test?" If that result is a blood alcohol level above 
$0.08 \%$, the accused must be found guilty. In the interest of certainty and efficiency the law has put him in the same situation as the motorist exceeding a speed limit. He cannot escape conviction by showing that due to his individual tolerance for alcohol his driving ability was not impaired any more than the speeding driver can by showing that in fact his speed was not dangerous.

In the case of offences the crucial element of which is thus mathematically defined and mechanically ascertained, the process of decision is also made practically mechanical. Nothing more than an elementary knowledge of COBOL would be required to program a computer for rendering quick and immediate judgments in such cases, provided the sentence was also mathematically predetermined because the first requirement for programming a computer is that any discretion must be excluded. When any discretion is to be exercised, a human being must take over.

Discretion really is law-making to a limited extent. This becomes apparent whenever it is systematically exercised in a given way. In such case, after a time, if the pattern is consistent, the manner in which the discretion is exercised becomes a judge-made law. Whether it is desirable that judicial discretion be thus exercised is highly debatable and it may well be that no attempt should be made to formulate a rule applicable to all discretionary judicial decisions. On the other hand the great danger is that unsystematic judicial discretion will result in a serious inequality of treatment under similar circumstances. The evolution of a judge-made rule is a way out of that difficulty. Unfortunately, such a development tends to destroy the flexibility inherent in discretionary powers.

Discretion also involves a risk that the consideration of individual cases will yield an unsatisfactory result on the whole. Hence the resort to minimum sentences. Everybody seems to agree that minimum sentences are undesirable as a rule because they are bound to be unnecessarily harsh under some circumstances. On the other hand, from a legislative point of view, they sometimes become necessary. Such may be the case for mandatory suspension of driving licences. It is well known that for many delinquent drivers, suspension is the only penalty that counts. If under a discretionary system the practical result, as was found to be the case in some jurisdictions, is that only about $10 \%$ of those convicted of an offence for which this penalty may be imposed are in fact condemned to suffer it, the risk of suffering it becomes so small that the deterrent effect is completely lost. Some studies, unfortunately unpublished, have shown that statistically there are no more than about $10 \%$ of such cases in which it would really be desirable that the suspension should not be inflicted in consequence of the conviction. If as a result of judges considering, as they must, individual cases instead of a whole series, what is administratively judged to be an unsatisfactorily small proportion of adequate penalties is meted out, the inevitable conclusion of the law-making authority will be a mandatory suspension, in other words, a minimum sentence. It is easy to see that to apply the law in such fashion is an administrative rather than a judicial task and it is in fact so considered in some jurisdictions. 
This also shows that a judicial task really involves law-making to a certain degree. In the case of a trial judge, his law-making is largely buried in his primary task of fact finding. In the appeal courts it is more often apt to be hidden in the choice of the criteria by which each case is decided. Under a common-law system, precedents always leave a possibility of further developments or refinements by way of distinction. Codification does not make as great a difference as is commonly supposed because the construction of statutes really leaves a wide area open to judicial law-making whenever the rules are stated in general terms as they must be in a code.

In fact, notwithstanding a draftsman's best efforts towards precision, a degree of indefiniteness lurks in every legislative provision. This is especially marked in constitutional provisions. Words actually lose much precision of meaning when used to define broad conceptions. The meaning of words is conventional, in final analysis it rests on generally accepted usage. It is really precise only to the extent that the category of acts or things described by any given word is susceptible of exact and objective definition. This is the kind of precision that is almost totally lacking in definitions of legal categories and concepts. To a large extent, the distinction between classes of laws is not based on an objective classification of the activities which are their subject matter but on the technique used in regulating them. Human activities as a whole are the subject matter of legislation and these activities are presently so interrelated that if every degree of connexity is considered, there is no limit to the possible extension of any given field of legislation as is strikingly illustrated by the recent report of the Economic Council respecting monopolies. ${ }^{3}$

It is therefore in theory only that there is a sharp and unyielding line of demarcation between the law-making and the law-finding processes. The courts have a not inconsiderable part in the totality of the legislative process, that is the shaping of the law as it is effectively applied in individual cases. However, the actual extent of the judicial part in the law-making process varies in any given field according to the activity of the law-writing process. Wherever legislative activity is very great, the tendency is towards detailed and frequently amended legislation sharply curtailing the field of judicial interpretation. On the contrary where, as in the law of torts, statutory enactments are rare and broadly worded a great deal is left to be decided by the courts.

In any case, the picture of judges blindly applying an inflexible law is idealistic and unrealistic. The truth is that an important personal equation enters into the processes of fact finding, legal construction and adjudication besides the application of judicial discretion in the many cases where it exists. One obvious consequence of the importance of the personal equation is that the actual selection of the members of a judiciary is a process of tremendous social importance deserving careful study. I commend you for undertaking it.

8 Economic Council of Canada, Interim Report on Competition Policy, July 1969. 